УДК 615.322:612.086

\title{
ПРИМЕНЕНИЕ ЭКСТРАКТОВ ЦВЕТКОВ ГЕОРГИНЫ, РОЗЫ И ПИОНА ДЛЯ ГИСТОЛОГИЧЕСКОГО ОКРАШИВАНИЯ*
}

\author{
(C) Т.А. Ииунина ${ }^{* *}$, А.А. Моспанова, А.Г. Архипова \\ Курский государственный медицинский университет, ул. Карла Маркса, 3, \\ Курск, 305041 (Россия), e-mail: ishunina@gmail.com
}

В серии предыдущих исследований была получена новая группа растительных красителей для гистологии на основе плодов, содержащих антоциановые пигменты. В данном исследовании изучены тинкториальные свойства спиртовых экстрактов лепестков георгины (Dahlia Cav.), розы (Rosa L.) и пиона (Paeonia L.), которые также содержат антоцианы. При выборе указанной группы растений основное внимание было уделено доступности растительного сырья, крупным размерам лепестков, облегчающим сбор, и наличию красной окраски, ассоциирующейся с наличием антоциановых пигментов. Показано, что на основе спиртовых экстрактов лепестков георгины можно изготовить краситель для окрашивания ядер и цитоплазмы клеток. При использовании настоек лепестков розы и пиона получены гистологические красители, относящиеся к разряду цитоплазматических. Все новые красители можно назвать протравными, так как их красящие свойства проявляются при использовании железного купороса, вступающего в реакции с растительными пигментами. С помощью сравнительного анализа впервые установлено, что растительные красители способны окрашивать ядра клеток и базофильные структуры цитоплазмы при преобладании в них моногликозидных разновидностей антоцианов. При наличии 3,5-дигликозидных антоцианов красители демонстрируют цитоплазматический характер.

Ключевые слова: георгин, роза, пион, антоцианы, моногликозиды, дигликозиды, гистологические красители.

\section{Введение}

Подавляющее большинство гистологических красителей, используемых для изучения клеток и тканей органов в биологии и медицине, получают на основе химических технологий промышленного производства, сосредоточенного в основном в зарубежных странах. В классификации гистологических красителей отдельно выделена подгруппа красителей растительного происхождения, основным официальным представителем которой является гематоксилин, получаемый из кампешевого дерева, произрастающего в Центральной Америке [1]. Таким образом, несмотря на обилие красящих пигментов растений, имеющих обширный ареал произрастания в России, эта группа гистологических красителей остается малоизученной и несистематизированной. В предыдущих исследованиях [2-4] нами продемонстрированы простые и недорогие методики получения ядерных красителей (для изучения ядер и базофильных структур цитоплазмы клеток) на основе плодов черноплодной рябины, бузины черной, черной смородины и винограда сорта «Изабелла», широко культивируемых в Центрально-Черноземном районе России. Общим для всех указанных плодов является значительное содержание антоциановых пигментов, имеющих в своей структуре оксониевый кислород, который может образовывать донорно-акцепторные связи с металлом-комплексообразователем протравных солей [5]. Наилучшие результаты гистологического окрашивания были получены при добавлении в спиртовые экстракты этих плодов медного купороса. При этом качество идентифика-

Ииунина Татьяна Александровна - доцент, кандидат медицинских наук, e-mail: ishunina@gmail.com Моспанова Ангелина Александровна - студентка, e-mail: ishunina@gmail.com

Архипова Алина Геннадьевна - студентка, e-mail: ishunina@gmail.com ции ядер и базофильных структур цитоплазмы различных клеток не уступало гематоксилину и другим импортным красителям, а в случае использования для изучения цитоархитеконики головного мозга даже превосходило их по большинству параметров.

\footnotetext{
* Данная статья имеет электронный дополнительный материал (приложение), который доступен читателям на сайте журнала. DOI: 10.14258/jcprm.2017031776s

Автор, с которым следует вести переписку.
} 
Принимая во внимание тот факт, что антоциановые пигменты содержатся не только в плодах, но и в других частях определенных видов растений, следующим этапом исследования стало изучение возможности приготовления гистологических красителей на основе цветков красного и темно-красного цвета. Условиями для отбора сырья были его доступность, крупные размеры лепестков, облегчающие сбор, и наличие красной окраски, гарантирующей наличие антоциановых пигментов при кислом значении рН [6], как и в случае упомянутых плодов. Эти критерии подошли цветкам георгины (Dahlia Cav.), poзы (Rosa L.) и пиона (Paeonia L.), широко культивирующихся на клумбах жителей Центрального района России.

\section{Экспериментальная часть}

Сбор сырья осуществлялся в период массового цветения с июня (пион) по август (георгина) 2016 года на территории Курской (пион) и Брянской (георгина) области. Темно-красные розы сорта «Freedom» были приобретены в цветочном киоске. Учитывая специфику антоциановых пигментов, способных легко гидратироваться и превращаться в водной среде, изменяя при этом заряд оксониевого кислорода с отрицательного, обеспечивающего базофильный (основной) характер красителя, на положительный, в качестве экстрагента, как и для плодов, был использован раствор с объемной долей этанола 90\%. Следует отметить, что только водной среды для изменения заряда антоцианов может быть недостаточно, и условия, при которых это происходит, до конца не изучены [7]. Тем не менее полагают, что при экстрагировании спиртом наблюдается самое высокое содержание антоциановых соединений и обеспечивается их большая стабильность и сохранность [8]. Для экстракции пигментов из цветочных лепестков хорошо подходит и раствор с объемной долей этанола 70\%, причем в этом случае возможно использование не только свежего, но и сухого сырья. Схема приготовления экстрактов выглядела следующим образом:

1. Отделение лепестков, их взвешивание и разминание.

2. Подготовка экстрагента - раствор с объемной долей этанола 90 или $70 \%$.

3. Смешивание сырья с экстрагентом в соотношениях $1: 1,1: 1,5$ и $1: 2$.

4. Настаивание при комнатной температуре (1,5 ч, 1 неделя, 2 недели, 1 месяц). Для экстрактов цветков георгины рекомендуемая длительность настаивания 1,5-2 ч, для экстрактов розы и пиона - 1-2 недели.

5. Очистка путем фильтрации через многослойную марлю.

Непосредственно перед окрашиванием добавляют железный купорос из расчета 2-2,5 г на 50 мл раствора и тщательно размешивают. В полученный краситель помещают депарафинированные гистологические срезы на 30-40 мин. После красителя срезы помещают в раствор с объемной долей этанола 70\% на 35 сек. Здесь происходит «дифференцировка» и удаление избытка красителя. Затем срезы переносят в растворы с объемной долей этанола 96\% (×2) и ксилол $(\times 2)$ на 45-60 сек в каждый и заключают под покровные стекла. Красящий раствор может быть использован повторно на протяжении как минимум 2-3 недель.

\section{Результаты и обсуждение}

Из изученных цветков были получены непрозрачные или малопрозрачные темно-красные растворы, окрашивающие марлю, руки и эмалированную посуду. Для подтверждения наличия антоциановых пигментов проведены качественные реакции с щелочным раствором бикарбоната натрия (табл. 1). Интенсивность окраски экстрактов находилась в прямой пропорциональной зависимости от соотношения сырье : экстрагент, была наибольшей при соотношении $1: 1$ и снижалась при уменьшении доли сырья в растворе. Однако результат гистологического окрашивания от изменений соотношения сырье : экстрагент в пределах от $1: 1$ до $1: 2$ практически не зависел (рис. 1 электронного приложения). При нагревании растворов в процессе экстракции интенсивность окраски как самих экстрактов, так и гистологических препаратов, полученных с их помощью, снижалась. Поэтому в окончательной схеме приготовления экстрактов рекомендуется настаивание при комнатной температуре. Значительного влияния длительности настаивания на исход окрашивания не отмечено за исключением лепестков георгины. В этом случае более интенсивное окрашивание препаратов отмечалось при настаивании в течение 1,5-2 ч (рис. 2 электронного приложения). Из протравных солей наилучшие результаты окрашивания получены при использовании железного купороса. Возможно применение медного купороса, но интенсивность гистологического окрашивания при этом снижается. 
Таблица 1. Изменение цвета и рН экстрактов при соотношении сырье : экстрагент $1: 1$ до и после добавления химических реагентов

\begin{tabular}{|c|c|c|c|c|}
\hline Реагент & $\begin{array}{c}\text { Экстракт лепестков } \\
\text { георгинов темно- } \\
\text { красных }\end{array}$ & $\begin{array}{c}\text { Экстракт лепестков } \\
\text { георгинов красно- } \\
\text { оранжевых }\end{array}$ & $\begin{array}{c}\text { Экстракт лепестков } \\
\text { пиона темно-красного }\end{array}$ & $\begin{array}{l}\text { Экстракт лепестков } \\
\text { розы темно-красной }\end{array}$ \\
\hline $\begin{array}{c}\text { Цвет и } \mathrm{pH} \\
\text { до реакции }\end{array}$ & $\begin{array}{c}\text { Красно- } \\
\text { коричневый, непро- } \\
\text { зрачный, } \mathrm{pH}=5\end{array}$ & $\begin{array}{c}\text { Темно-красный с оран- } \\
\text { жевым оттенком, мало- } \\
\text { прозрачный, } \mathrm{pH}=4-5\end{array}$ & $\begin{array}{c}\text { Темно-красный, не- } \\
\text { прозрачный, рН ин- } \\
\text { дикатор менял значе- } \\
\text { ния } 3 \rightarrow 2 \rightarrow 1\end{array}$ & $\begin{array}{c}\text { Темно-красный, ма- } \\
\text { лопрозрачный, } \mathrm{pH} \\
\text { индикатор менял зна- } \\
\text { чения } 3 \rightarrow 2 \rightarrow 1\end{array}$ \\
\hline $\begin{array}{c}+ \text { раствор } \\
\text { гидрокарбоната } \\
\text { натрия }\end{array}$ & $\begin{array}{c}\text { Покраснел, } \\
\text { темно-красный }\end{array}$ & $\begin{array}{c}\text { Покраснел, } \\
\text { ярко-красный }\end{array}$ & $\begin{array}{c}\text { Потемнел, приобрел } \\
\text { коричневый оттенок, } \\
\text { на стенке посуды } \\
\text { синий }\end{array}$ & $\begin{array}{c}\text { Потемнел, стал чер- } \\
\text { ным, на стенке посу- } \\
\text { ды синий }\end{array}$ \\
\hline $\begin{array}{c}\text { железный } \\
\text { купорос }\end{array}$ & $\begin{array}{l}\text { Темно-зеленый, } \\
\text { непрозрачный, } \\
\text { pH = } 8\end{array}$ & $\begin{array}{c}\text { Желто-зеленый, образо- } \\
\text { вался осадок, рН = } 6\end{array}$ & $\begin{array}{c}\text { Черный, непрозрач- } \\
\text { ный, } \mathrm{pH}=8-9\end{array}$ & $\begin{array}{c}\text { Черный (темно- } \\
\text { коричневый), непро- } \\
\text { зрачный, } \mathrm{pH}=8-9\end{array}$ \\
\hline
\end{tabular}

На основе экстрактов лепестков пиона и розы получены стойкие цитоплазматические красители черного и коричневого цвета (рис. 3 и 4 электронного приложения). Из экстрактов лепестков георгинов темно-красного цвета приготовлен краситель, способный окрашивать как ядра, так и цитоплазму клеток в зеленый цвет (рис.). Более того, он подходит и для изучения срезов головного мозга, где четко дифференцируются нейроны (рис. В) и хорошо визуализируются нервные волокна (рис. Г). При использовании экстрактов красно-оранжевых георгинов результаты окрашивания были идентичными. Однако более бледный желтый цвет окрашенных структур в меньшей степени подходит для гистологических исследований. Предположительно, механизм окраски ядер в этом случае может напоминать описанный ранее для красителей на основе антоциан-содержащих плодов [4]. Но при сравнении красителей на основе антоциансодержащих плодов и цветков выявляются существенные отличия (табл. 2).
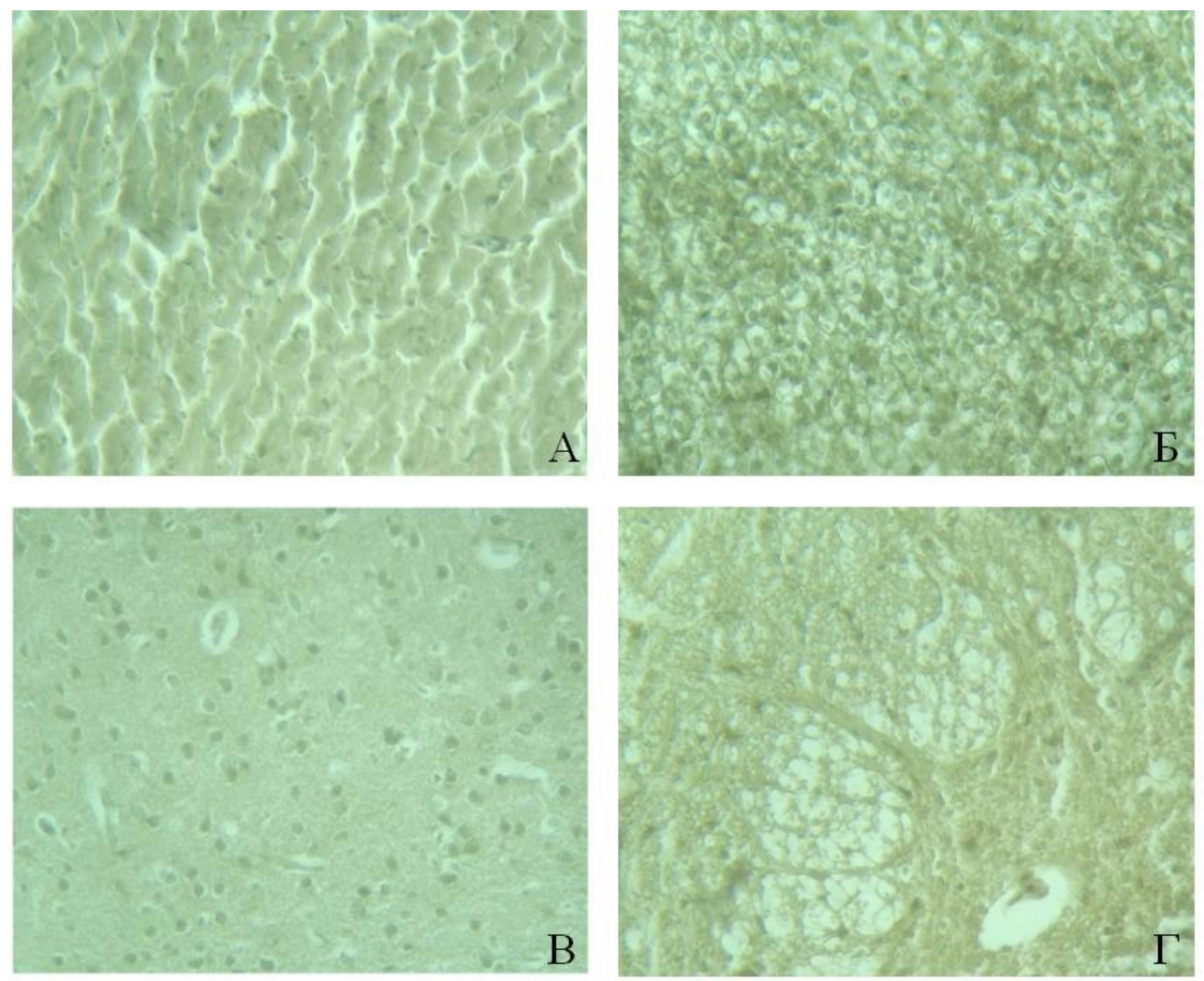

Окраска срезов новым красителем на основе спиртового экстракта (1 : 1, 1,5 ч) лепестков георгины: (А) сердца, (Б) печени, (В, Г) головного мозга. Ув. × 400 
Таблица 2. Отличия гистологических красителей на основе антоциан-содержащих плодов и цветков

\begin{tabular}{|c|c|c|c|c|}
\hline $\begin{array}{l}\text { Сравниваемый } \\
\text { параметр }\end{array}$ & $\begin{array}{c}\text { Краситель на основе } \\
\text { плодов черноплод- } \\
\text { ной рябины }\end{array}$ & $\begin{array}{c}\text { Краситель на основе } \\
\text { цветков георгинов }\end{array}$ & $\begin{array}{c}\text { Краситель на основе } \\
\text { цветков пиона }\end{array}$ & $\begin{array}{c}\text { Краситель на основе } \\
\text { цветков розы }\end{array}$ \\
\hline Протравная соль & Медный купорос & Железный купорос & Железный купорос & Железный купорос \\
\hline $\begin{array}{l}\text { Цвет при добавлении } \\
\text { щелочного раствора } \\
\text { бикарбоната натрия }\end{array}$ & $\begin{array}{c}\text { Темнеет, } \\
\text { черный или темно- } \\
\text { фиолетовый }\end{array}$ & $\begin{array}{c}\text { Не меняет оттенок } \\
\text { цвета, } \\
\text { красный }\end{array}$ & $\begin{array}{c}\text { Темнеет, } \\
\text { темно-коричневый }\end{array}$ & $\begin{array}{l}\text { Темнеет, } \\
\text { черный }\end{array}$ \\
\hline $\begin{array}{l}\text { pH до протравной } \\
\text { соли }\end{array}$ & $0-1$ & 5 & $3 \rightarrow 2 \rightarrow 1$ & $3 \rightarrow 2 \rightarrow 1$ \\
\hline $\begin{array}{l}\text { pH после протравной } \\
\text { соли }\end{array}$ & $0-1$ & 8 & $8-9$ & $8-9$ \\
\hline $\begin{array}{l}\text { Соотношение сы- } \\
\text { рье : экстрагент }\end{array}$ & $1,3: 1$ & $1: 1$ & $1: 1-1: 2$ & $1: 1-1: 2$ \\
\hline Тип красителя & Ядерный & $\begin{array}{c}\text { Ядерно- } \\
\text { цитоплазматический }\end{array}$ & Цитоплазматический & Цитоплазматический \\
\hline Основные антоцианы & $\begin{array}{c}\text { Цианидин 3- } \\
\text { галактозид } \\
\text { Цианидин 3- } \\
\text { арабинозид [9] }\end{array}$ & $\begin{array}{c}\text { Пелларгонидин 3-(6- } \\
\text { малонил-гликозид)- } \\
\text { 5-гликозид } \\
\text { Цианидин 3,5- } \\
\text { дигликозид [18] }\end{array}$ & $\begin{array}{c}\text { Пеонидин 3,5- } \\
\text { дигликозид [13] }\end{array}$ & $\begin{array}{l}\text { Цианидин 3,5-ди-О- } \\
\text { гликозид } \\
\text { Пелларгонидин 3,5- } \\
\text { ди-О-гликозид [16] }\end{array}$ \\
\hline
\end{tabular}

При сравнительном анализе химического состава сырья становится ясно, что ядерный характер гистологических красителей на основе плодов черноплодной рябины, бузины черной, черной смородины и винограда сорта «Изабелла» [4] скорее всего обусловлен значительным преобладанием в них 3-моногликозидных антоцианидинов. Основными антоцианами плодов черноплодной рябины являются цианидин 3-галактозид, цианидин 3-арабинозид [9], бузины черной - цианидин 3-самбубиозид [10], черной смородины - 3-гликозиды и 3-рутинозиды цианидина и дельфинидина [11], винограда сорта «Изабелла» - мальвидин 3-моногликозид [12]. Несмотря на наличие антоциановых пигментов в цветках пиона [13-15] и розы [16, 17], красители на их основе - цитоплазматические, что, по всей видимости, обусловлено наличием 3,5-дигликозидных форм антоцианов. рН этих экстрактов лабильно и повышается после добавления железного купороса. Согласно данным [18], темно-красные цветки георгин накапливают антоцианы и флавоны апигенин и лютеолин. Отсутствие изменения цвета в щелочном растворе не типично для антоцианов, но может быть объяснено высоким содержанием флавонов и уникальным для георгин антоцианидином пелларгонидином 3-(6-малонил-гликозид)5-гликозидом [19]. Удивительно появление ядерного окрашивания при $\mathrm{pH}=8$. Для всех красителей на основе плодов обязательным было низкое значение $\mathrm{pH}$ в пределах 0-1. При его повышении наблюдалось снижение ядерного и усиление цитоплазматического характера окрашивания. Логичны различия тинкториальных свойств экстрактов георгинов темно-красного и красно-оранжевого цвета, так как оранжевая окраска обусловлена низким содержанием антоцианов и наличием флавонов и бутеина (халкон). Следовательно, ядерный тип гистологического красителя растительного происхождения все-таки определяется наличием антоцианов, причем преимущественно моногликозилированных разновидностей цианидина и зависит от их количества. Так, наилучшие ядерные красители [4] получены из плодов черноплодной рябины и бузины черной с максимальным содержанием антоцианов [5]. Основными антоцианидинами в этом случае являются моногликозиды цианидина $[9,10]$. В цветках георгин находятся как дигликозиды: пелларгонидин 3-(6-малонил-гликозид)-5гликозид и цианидин 3,5-дигликозид), так и моногликозиды: цианидин 3-гликозид и пелларгонидин 3гликозид [19]. Уместно предположить, что окраска ядер клеток при использовании экстракта георгин связана с наличием моногликозида цианидина, как у плодов, а наблюдаемое окрашивание цитоплазмы обусловлено сочетанным влиянием дигликозидов, как у розы и пиона, и флавонов.

\section{Выводы}

На основе спиртовых экстрактов антоциан-содержащих цветков георгин, пиона и розы красного цвета получены новые гистологические красители протравного типа. Красители на основе экстрактов пиона и розы - цитоплазматические, а на основе георгин - ядерно-цитоплазматические. С помощью сравнительного анализа впервые установлено, что приготовление гистологических красителей ядерного типа возможно на основе растительного сырья с очень высоким содержанием моногликозидов цианидина. Наличие дигликозидных форм антоцианов ассоциируется с отсутствием ядерной окраски на гистологических препаратах. 


\section{Список литературы}

1. Коржевский Д.Э. Применение гематоксилина в гистологической технике // Морфология. 2007. Т. 132. №6. C. $77-82$.

2. Ишунина Т.А., Солоненко О.В. Гистологический краситель на основе антоцианов ягод черноплодной рябины (Aronia melanocarpa) // Морфологические ведомости. 2014. №4. С. 58-61.

3. Ишунина Т.А. Гистологические красители на основе экстрактов ягод винограда и черной смородины // Морфологические ведомости. 2015. №4. С. 65-68.

4. Ишунина Т.А. Разработка технологии приготовления красителей для гистологических целей на основе экстрактов растений // Структура и физико-химические свойства целлюлоз и нанокомпозитов на их основе. Петрозаводск, 2016. С. 111-115.

5. Horbowicz M., Kossan R., Grzesiuk A., Debski H. Anthocyanins of fruits and vegetables - their occurrence, analysis and role in human nutrition // Veg Crops Res Bull. 2008. Vol. 68. Pp. 5-22.

6. Ng J., Smith S.D. How to make a red flower: the combinatorial effect of pigments // AoB PLANTS. 2016. Vol. 8. plw013; doi:10.1093/aobpla/plw013.

7. Болотов В.М., Нечаев А.П., Сарафанова Л.А. Пищевые красители: классификация, свойства, анализ, применение. СПб., 2008. 240 с.

8. Саввин П.Н., Комарова Е.В., Болотов В.М., Шичкина Е.С. Исследование натуральных каротиноидноантоциановых красителей // Химия растительного сырья. 2010. №4. С. 135-138.

9. Oszmianski J., Sapis J. Anthocyanins in fruits of Aronia Melanocarpa (chokeberry) // J. Food Sci. 1988. Vol. 53. N4. Pp. 1241-1242.

10. Veberic R., Jacopic J., Stampar F., Schmitzer V. European elderberry (Sambucus Nigra L.) rich in sugars, organic acids, anthocyanins and selected polyphenols // Food Chem. 2009. Vol. 114. Pp. 511-515.

11. Петрова С.Н., Кузнецова А.А. Состав плодов и листьев смородины чёрной Ribes Nigrum (обзор) // Химия растительного сырья. 2014. №4. С. 43-50.

12. Flamini R., Tomasi D. The anthocyanin content in berries of the hybrid grape cultivars Clinton and Isabella // Vitis. 2000. Vol. 39. N2. Pp. 79-81.

13. Zhao D.Q., Wei M.R., Liu D., Tao J. Anatomical and biochemical analysis reveal the role of anthocyanins in flower coloration of herbaceous peony // Plant Physiol. Biochem. 2016. Vol. 102. Pp. 97-106.

14. Jia N., Shu Q-Y., Wang D-H., Wang L-S., Liu Z-A., Ren H-X. Identification and characterization of anthocyanins by high-performance liquid chromatography-electrospray ionization-mass spectrometry in herbaceous peony species // J. Amer. Soc. Hort. Sci. 2008. Vol. 133. N3. Pp. 418-426.

15. Hosoki T., Seo M. Flower anthocyanins of herbaceous peony // Bull. Fac. Agr. Shimane Univ. 1991. Vol. 25. Pp. 11-14.

16. Deineka L., Deineka V., Tokhtar V., Martynova N. Rose flower petals: rich source of anthocyanins // RJPBCS. 2015. Vol. 6. N5. Pp. 944-950.

17. Lee J.H., Lee H.J., Choung M.G. Anthocyanin compositions and biological activities from the red petals of Korean edible rose (Rosa hybrid cv. Noblered) // Food Chem. 2011. Vol. 129. N2. Pp. 272-278.

18. Ogata J.U.N., Sakamoto T., Yamaguchi M., Kawanobu S., Yoshitama K. Isolation and characterization of anthocyanin 5-O-glucosyltransferase from flowers of Dahlia variabilis // J. Plant Physiol. 2001. Vol. 158. N6. Pp. 709-714.

19. Harborne J.B., Boardley M. The widespread occurrence in nature of anthocyanins as zwitterions // Z. Naturforsch. 1985. Pp. 305-308. 
Ishunina T.A.*, Mospanova A.A., Arkhipova A.G. THE USE OF EXTRACTS OF DAHLIA, ROSE AND PEONY FLOWERS FOR HISTOLOGICAL STAINING

Kursk State Medical University, ul. Karla Marxa, 3, Kursk, 305041 (Russia), e-mail: ishunina@gmail.com.

In a series of previous studies a new group of plant dyes was developed for histology on the basis of the fruit extracts containing anthocyanin pigments. In the present study the tinctorial properties of ethanol extracts of dahlia (Dahlia Cav.), rose (Rosa L.) and peony (Paeonia L.) petals which also contain anthocyanins were evaluated. The choice of the plant group mentioned above was based on the availability of vegetable raw materials, the large size of the petals for the easy pickup and on the red color associated with the presence of anthocyanins. On the basis of ethanol extracts of dahlias' petals the dye for staining both the cellular nuclei and the cytoplasm was obtained. When using the petals of rose and peony flowers cytoplasmic histological dyes were received. All new dyes belong to the group of mordant stains, since their staining properties for histological slides are expressed when using iron sulphate that reacts with vegetable pigments. With the help of comparative analysis it was found for the first time that vegetable dyes are able to stain the cell nuclei and basophilic structures of the cytoplasm if they contain predominantly the monoglycoside varieties of anthocyanins. In the presence of 3,5-diglucoside anthocyanins the dyes demonstrate the cytoplasmic nature.

Keywords: Dahlia, rose, peony, anthocyanins, monoglycosides, diglucosides, histological dyes.

\section{References}

1. Korzhevskii D.E. Morfologiia, 2007, vol. 132, no. 6, pp. 77-82. (in Russ.).

2. Ishunina T.A., Solonenko O.V. Morfologicheskie vedomosti, 2014, no. 4, pp. 58-61. (in Russ.).

3. Ishunina T.A. Morfologicheskie vedomosti, 2015, no. 4, pp. 65-68. (in Russ.).

4. Ishunina T.A. Struktura i fiziko-khimicheskie svoistva tselliuloz i nanokompozitov na ikh osnove. [Structure and physicochemical properties of celluloses and nanocomposites based on them]. Petrozavodsk, 2016, pp. 111-115. (in Russ.).

5. Horbowicz M., Kossan R., Grzesiuk A., Debski H. Veg Crops Res Bull., 2008, vol. 68, pp. 5-22.

6. Ng J., Smith S.D. AoB PLANTS, 2016, vol. 8, plw013; doi:10.1093/aobpla/plw013.

7. Bolotov V.M., Nechaev A.P., Sarafanova L.A. Pishchevye krasiteli: klassifikatsiia, svoistva, analiz, primenenie. [Food colors: classification, properties, analysis, application]. St. Petersburg, 2008, 240 p. (in Russ.).

8. Savvin P.N., Komarova E.V., Bolotov V.M., Shichkina E.S. Khimiia rastitel'nogo syr'ia, 2010, no. 4, pp. $135-138$. (in Russ.).

9. Oszmianski J., Sapis J. J. Food Sci., 1988, vol. 53, no. 4, pp. 1241-1242.

10. Veberic R., Jacopic J., Stampar F., Schmitzer V. Food Chem., 2009, vol. 114, pp. 511-515.

11. Petrova S.N., Kuznetsova A.A. Khimiia rastitel'nogo syr'ia, 2014, no. 4, pp. 43-50. (in Russ.).

12. Flamini R., Tomasi D. Vitis., 2000, vol. 39, no. 2, pp. 79-81.

13. Zhao D.Q., Wei M.R., Liu D., Tao J. Plant Physiol. Biochem., 2016, vol. 102, pp. 97-106.

14. Jia N., Shu Q-Y., Wang D-H., Wang L-S., Liu Z-A., Ren H-X. J. Amer. Soc. Hort. Sci., 2008, vol. 133, no. 3, pp. $418-426$.

15. Hosoki T., Seo M. Bull. Fac. Agr. Shimane Univ., 1991, vol. 25, pp. 11-14.

16. Deineka L., Deineka V., Tokhtar V., Martynova N. RJPBCS, 2015, vol. 6, no. 5, pp. 944-950.

17. Lee J.H., Lee H.J., Choung M.G. Food Chem., 2011, vol. 129, no. 2, pp. 272-278.

18. Ogata J.U.N., Sakamoto T., Yamaguchi M., Kawanobu S., Yoshitama K. J. Plant Physiol., 2001, vol. 158, no. 6, pp. 709-714.

19. Harborne J.B., Boardley M. Z. Naturforsch., 1985, pp. 305-308.

Received January 26, 2017

Revised February 18, 2017

\footnotetext{
* Corresponding author.
} 